\title{
Quality Management in Training Companies
}

\author{
Ana Fernandes ${ }^{1}(\mathbb{D})$, Henrique Vicente ${ }^{1,2}$ (D), \\ Margarida Figueiredo ${ }^{1,3}$ (D) , Jorge Ribeiro ${ }^{4}$ (D), and José Neves ${ }^{2(\bowtie)}$ (D) \\ ${ }^{1}$ Departamento de Química, Escola de Ciências E Tecnologia, \\ Universidade de Évora, Évora, Portugal \\ anavilafernandes@gmail.com, \{hvicente,mtf $\} @ u e v o r a . p t ~$ \\ ${ }^{2}$ Centro Algoritmi, Universidade do Minho, Braga, Portugal \\ jneves@di.uminho.pt \\ ${ }^{3}$ Centro de Investigação em Educação e Psicologia, \\ Universidade de Évora, Évora, Portugal \\ ${ }^{4}$ Escola Superior de Tecnologia e Gestão, ARC4DigiT - Applied Research \\ Center for Digital Transformation, Instituto Politécnico de Viana do Castelo, \\ Viana do Castelo, Portugal \\ jribeiro@estg.ipvc.pt
}

\begin{abstract}
This study was carried out in training companies and aims to evaluate customer satisfaction. It focusses at the Organizations' Quality-of-Management $(Q o M)$ that is in itself a major competitive advantage to differentiate them. Indeed, the universe of discourse is set in order to consider not only the complex relationships among the entities that populate it, but also to take into account its inner structure, where incomplete, unknown or even self-contradictory information or knowledge are present. One's goal is at the development of a comprehensive and integrated computational model to ensure the Organizations' Performance and its QoM in order to fulfill customer's requirements. It is based on a Logic Programming approach to Knowledge Representation and Reasoning and grounded on an Artificial Neural Networks approach to computing.
\end{abstract}

Keywords: Artificial Intelligence $\cdot$ International Standard ISO 9001 Quality-of-Management · Logic Programming Knowledge Representation and Reasoning - Artificial Neural Networks 